\title{
A RADIOCARBON CHRONOLOGY FOR HUMAN-INDUCED ENVIRONMENTAL CHANGE ON MANGAIA, SOUTHERN COOK ISLANDS, POLYNESIA
}

\author{
P. V. KIRCH', J. R. FLENLEY $Y^{2}$ and D. W. STEADMAN ${ }^{3}$
}

\begin{abstract}
A suite of $23{ }^{14} \mathrm{C}$ age determinations, from a well-stratified rockshelter and from 3 pollen cores on Mangaia Island is reported. The rockshelter has yielded significant evidence for avifaunal extinctions during the period cal. A.D. 1000-1600. The Lake Tiriara pollen cores span a period from ca. $6500 \mathrm{cal}$. B.P. to the present, and palynological analysis of the TIR 1 core indicates major anthropogenic disturbance on the island's vegetation after ca. 1600 cal. B.P. These sites, and the radiocarbon ages associated with them, provide the first chronologically secure evidence for human impacts on the island ecosystems of the southern Cook Islands.
\end{abstract}

\section{INTRODUCTION}

For years, anthropologists and archaeologists tacitly assumed that prehistoric Polynesians had little impact on their island ecosystems; island environments were regarded as essentially static backdrops for colonizing human cultures. Similar assumptions were made by biogeographers, who viewed most change as having occurred after the arrival of Europeans. Thus, such classic studies of island biogeography as MacArthur and Wilson (1967) accepted historic-period data on animal and plant species frequencies and distributions as representing 'natural' situations.

Recently, a spate of archaeological, paleontological, palynological and geoarchaeological investigations in Polynesia has demonstrated that prehistoric Polynesians, in fact, had a significant impact on their insular ecosystems (e.g., Kirch 1982, 1983; Steadman 1989; Olson \& James 1984; Pregill \& Dye 1989; Christensen \& Kirch 1986; Flenley \& King 1984; McGlone 1983; Kirch \& Yen 1982; Hughes et al. 1982). It is now evident that Polynesians often precipitated major changes in their island environments, including deforestation and other forms of habitat disturbance and destruction, extinction and/or extirpation of endemic biota, introduction of competitive species of weeds and pests, and soil erosion with increased rates of alluvial sedimentation in valley bottoms. From the human perspective, not all of these impacts were necessarily deleterious; alluviation sometimes enhanced island agricultural regimes (Spriggs 1986). Nonetheless, from a biotic perspective, the impacts of Polynesians on endemic and vulnerable island biotas (Fosberg 1963) were frequently devastating. Some of the most dramatic evidence has come from archaeological assemblages of bird bones, indicating massive extinction of native land birds in such island groups as Hawaii, the Marquesas, Society and Cook Islands (Steadman 1989).

In order to learn more about how the prehistoric Polynesians modified island ecosystems, we initiated an interdisciplinary study of human-induced environmental change on Mangaia Island, in the Southern Cook Islands (Fig. 1), with a first season of fieldwork in 1989. Our approach applies the methods of archaeology (PVK), avian paleontology (DWS), and palynology (JF) in a coordinated field and laboratory study. Mangaia was chosen as the field site because: 1) preliminary work by DWS had revealed important bone assemblages of extinct land birds with cultural associations (Steadman 1985, 1987); 2) several small lakes on the island seemed suitable for taking sediment cores; 3) ethnohistoric data suggested severe deforestation and cultural stress resulting from overpopulation and competition for limited agricultural lands (Gill 1894; Buck 1934). Prior

\footnotetext{
${ }^{\text {I} D e p a r t m e n t ~ o f ~ A n t h r o p o l o g y, ~ U n i v e r s i t y ~ o f ~ C a l i f o r n i a, ~ B e r k e l e y, ~ C a l i f o r n i a ~} 94720$ USA

${ }^{2}$ Department of Geography, Massey University, Palmerston North, New Zealand

${ }^{3}$ Biological Survey, New York State Museum, Albany, New York 12230 USA
} 


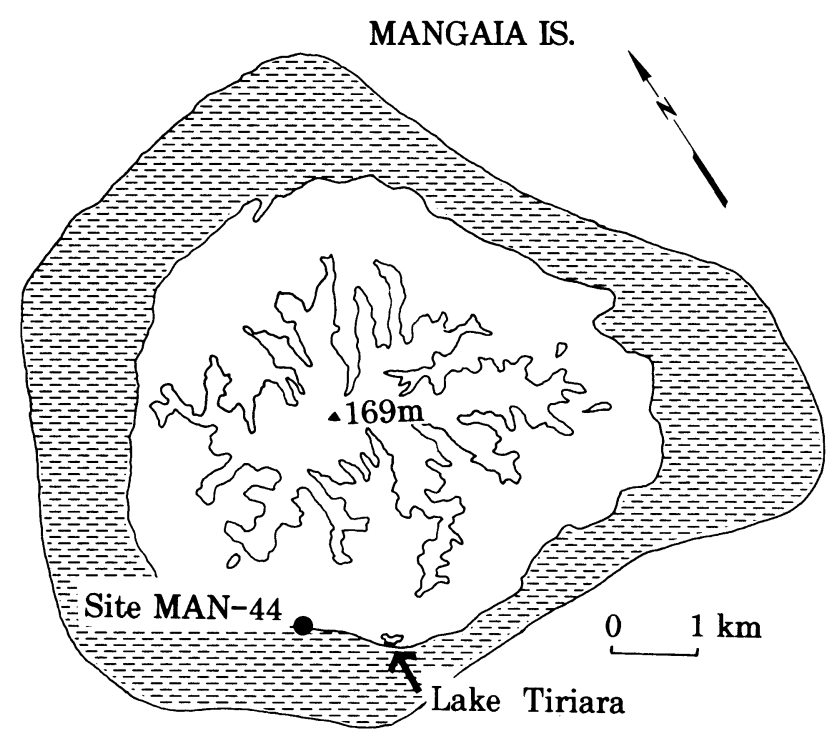

$\square$ Volcanics

Fig. 1. Map of Mangaia Island, showing the locations of Tangatatau (Site MAN-44) and Lake Tiriara

to our study, the island had been only cursorily investigated from an archaeological perspective (Bellwood 1978).

Mangaia $\left(21^{\circ} 55^{\prime} \mathrm{S}, 157^{\circ} 55^{\prime} \mathrm{W}\right)$ is a small island $\left(52 \mathrm{~km}^{2}\right)$ at the southeast end of the Cook Islands. Geologically, Mangaia is part of the Cook-Austral Island chain (Turner \& Jarrard 1982). A central core of highly weathered volcanics ( $c a .18$ My B.P.) with radial stream drainage is surrounded by a ring of emerged reef limestones dating to at least 110 ka B.P. (Marshall 1927; Stoddart, Spencer \& Scoffin 1985). The central volcanic cone is heavily eroded, and supports only an open, pyrophytic association of scrub Pandanus, Casuarina, Dicranopteris (Gleichenia) fern, and grasses. The limestone terrain (called makatea) supports a depauperate rainforest dominated by the trees, Hernandia moerenhoutiana, Guettarda speciosa, Elaeocarpus tonganus, Pandanus tectorius and Ficus prolixa (Merlin 1991). At European contact and into the present century, the Polynesian occupants have practiced intensive pondfield irrigation of taro (Colocasia esculenta) on the hydromorphic alluvial soils of the radial stream valley bottoms.

Our 1989 fieldwork focused on the Veitatei District, which is both a natural geomorphic unit (a radial stream drainage system) and a traditional Polynesian chiefdom territory. Following initial reconnaissance, during which a number of late prehistoric habitation and temple sites (marae) were recorded, we decided to concentrate our efforts on two projects. The first was intensive excavation of a large rockshelter site (Tangatatau, Site MAN-44), which promised to yield a well-stratified sequence of cultural deposits. The second was coring of Lake Tiriara in order to obtain a continuous sediment sequence for pollen analysis. Figure 1 shows both the Tangatatau and the Lake Tiriara sites.

We report here a suite of $23{ }^{14} \mathrm{C}$ age determinations from Mangaia; 15 of these are from our excavations at the stratified Tangatatau rockshelter site, and 8 are from sediment cores in Lake 
Tiriara. Following a brief summary of the sites and a review of the dates, we discuss the significance of these ${ }^{14} \mathrm{C}$ determinations, paying special attention to the chronology of human occupation of Mangaia and the impact of such occupation on the island ecosystem.

\section{THE TANGATATAU SITE (MAN-44)}

Tangatatau is the local Mangaian name for a large rockshelter formed by an overhanging block of the inner cliff of the makatea limestone in Veitatei District (Fig. 1). The rockshelter lies at the base of a long, gentle volcanic slope rising northward toward the interior of the island. Lake Tiriara, where our pollen cores were obtained, lies approximately $0.9 \mathrm{~km}$ southeast of the rockshelter.

Our reconnaissance survey of Veitatei indicated that Tangatatau (designated site MAN-44 in our island-wide catalog of archaeological sites) was the most likely site to yield a well-stratified cultural sequence, due to the extent of habitable surface area under the drip line $\left(225 \mathrm{~m}^{2}\right)$, and because the surface contours suggested considerable depth of deposit. Therefore, we focused our excavations on this site for three weeks in July-August 1989. A more complete report on these excavations is forthcoming (Kirch \& Steadman, Archaeological excavations at Tangatatau Rockshelter, Mangaia Island, ms. in preparation); here we mention only a few points critical to understanding the context of the ${ }^{14} \mathrm{C}$ determinations.

Our primary excavation was a $1 \times 5 \mathrm{~m}$ trench (grid units $\mathrm{C} 30-\mathrm{G} 30$ ) bisecting the main rockshelter floor from the rear shelter wall to a point some 3-4 m from the drip line. A $1 \mathrm{~m}^{2}$ test unit (grid unit F10) also was excavated in a second open floor area $20 \mathrm{~m}$ west of the main trench. Radiocarbon age determinations were obtained from both the main trench and the F10 test unit, revealing comparable age-depth sequences for both sectors of the site (see below).

The stratigraphy of the main trench was extremely complex, with 36 discrete depositional units and features identified in the west face, which will be described and illustrated in detail in Kirch and Steadman (ms. in preparation). The section has a total depth of about $1.6 \mathrm{~m}$. For purposes of correlation and tabulation of excavated materials, we have designated 10 'analytic zones' for the main trench, labeled $\mathrm{A}$ to $\mathrm{J}$ (from top to bottom of the section), and determined independently of the radiocarbon and faunal data. In brief, the base of the section (Zone $J$ ) consists of a reddishyellow (5 YR 7/6-7) fine, silty-clay derived from decomposed limestone, containing numerous small terrestrial gastropod shells, and representing the prehuman occupation phase. Overlying this is a set of relatively massive layers and beds (Zones I-G) of brown to dark brown (7.5 YR 5/2 to 7.5 YR 4/2) ashy midden, with large charcoal pieces scattered throughout. This early phase appears to represent a period of continuous human occupation of the shelter as a primary residential site. At ca. $0.6 \mathrm{~m}$ below surface, there is a marked change in the sedimentary regime, with the initiation of a series of discrete lenses of yellowish-red (5 YR 4-5/6) sticky clay (Zones F-B), intercalated with thin shell-midden beds, finely bedded ash deposits and various oven and hearth deposits. This upper stratigraphic regime evidently resulted from periodic fluvial deposition of volcanic clays onto the shelter floor, alternating with phases of occupation and shell-midden dumping. The uppermost $10 \mathrm{~cm}$ of the section (Zone A) consists of a horizontally continuous deposit of dark reddish-brown (5 YR 3/2) ashy silt, rich in charcoal and undecomposed organic materials (leaves, Pandanus fruit and wood fragments) mixed with a few historic-period artifacts.

The stratigraphic sequence in grid unit F10 was apparently less complex than in the main trench, although the presence of a large earth oven feature made interpretation of the section more tenuous.

The occupation deposits yielded a rich array of artifacts as well as both vertebrate and invertebrate faunal materials. The main artifact classes include fishing gear (especially one-piece fishhooks), 
coral and urchin-spine abrading tools, stone adzes, shell pendants, bone tattooing chisels, a coral gaming stone and large numbers of chipped basalt and chert flakes and cores. The one-piece fishhooks display a significant sequence of change, with hooks of exotic pearl shell (Pinctada sp.) in the lower occupation component, followed by hooks manufactured from the locally occurring Turbo setosus in the upper component. The basalt adzes also reveal a sequence of typological change, from untanged adzes in the lower component to typical, late-prehistoric Cook Islands tanged adzes in the upper component.

The invertebrate faunal materials are dominated by mollusks, largely species that occur along the narrow, exposed fringing reef that surrounds Mangaia Island. These include both gastropods and bivalves. Our analysis of these mollusks is still in process, but it is evident that there is statistically significant size reduction from early to late strata in at least the Turbo shells, probably due to intense human predation and exploitation of this species for food. Also present in the invertebrate faunal assemblage are crustaceans and echinoderms.

We recovered a total of 11,179 vertebrate faunal specimens from the $6 \mathrm{~m}^{2}$ excavated. Of these, the majority $(90 \%)$ are bones of small reef fish such as scarids, labrids and acanthurids. Of particular note, however, are 212 bones of native species of birds. These include both seabirds (in the genera Puffinus, Pterodroma, Nesofregetta, Phaethon, Fregata, Anous, Procelsterna and Gygis) and land birds (in the genera Anas, Pluvialis, Gallirallus, Porzana, Gallicolumba, Ptilinopus, Ducula, Vini, Halcyon and Acrocephalus). The land birds are of particular interest, as many of the species represented in the rockshelter midden are extinct and/or extirpated on Mangaia (Steadman \& Kirch 1990). Except for a single bone of Ptilinopus, the extinct/extirpated species are confined to the lower occupation component of the site (Analytic Zones J-G). Also well represented in these lower stratigraphic zones are bones of the indigenous fruit bat, Pteropus tonganus, today a threatened species represented by $<200$ individuals. The vertebrate faunal assemblage also documents the introduction to the island in prehistory of the Polynesian rat (Rattus exulans) and of the domestic pig (Sus scrofa); the bones of these latter species are especially prevalent in the upper, laterprehistoric occupation deposits.

\section{THE TANGATATAU RADIOCARBON SEQUENCE}

The $15{ }^{14} \mathrm{C}$ samples from Tangatatau were selected at the close of the field season, out of a total of 22 potentially datable charcoal samples. Priority was given to samples collected from discrete features (e.g., lenses, earth ovens, hearths) in well-controlled stratigraphic contexts. Samples were also selected to provide relatively complete vertical representation of the stratigraphic column. Four samples are from unit $\mathrm{F} 10$, and the other 11 samples from the $\mathrm{C} 30-\mathrm{G} 30$ main trench. In virtually all cases, the dated charcoal was a mixture of carbonized wood, candlenut (Aleurites moluccana) endocarp fragments and Pandanus tectorius drupes. All samples were collected directly into foil and then bagged in heavy polyethylene bags.

All samples were processed and analyzed by Beta Analytic, Inc. The charcoal was pretreated by first examining for rootlets, followed by a hot acid wash to eliminate carbonates. Samples were then repeatedly rinsed to neutrality and subsequently given a hot alkali soaking to remove humic acids. After rinsing to neutrality, another acid wash followed, with subsequent rinsing to neutrality. Benzene syntheses and counting proceeded normally (M. Tamers, personal communication, 21 Sept. 1989). Six of the samples proved to be quite small after pretreatment (Beta-32816, -32817, $-32824,-32835,-32826$ and -32829 ), and were thus accorded extended counting times ( $4 \times$ the normal counting period), in order to reduce statistical error. The ${ }^{13} \mathrm{C} /{ }^{12} \mathrm{C}$ ratios were measured for all samples to establish ${ }^{13} \mathrm{C}$ adjusted, "conventional ${ }^{14} \mathrm{C}$ ages" (Stuiver \& Polach 1977). These 
conventional age determinations, ${ }^{13} \mathrm{C} /{ }^{12} \mathrm{C}$ values, and details of all samples are presented at the end of this paper.

Calibration of ages for secular effects follow Stuiver and Becker (1986) for samples grown in terrestrial environments. Calibrations and probability estimates were made using Revision 2.0 of the "Calib" FORTRAN microcomputer program (Stuiver \& Reimer 1986).

The $11{ }^{14} \mathrm{C}$ age determinations from the main trench excavations are plotted in Figure 2 as calibrated A.D. ranges at $1 \sigma$, according to stratigraphic position (analytic zones); the 4 age determinations from the F10 grid unit are similarly plotted in Figure 3. With three exceptions, these age determinations fall into a consistent stratigraphic order. The exceptions are samples Beta-32817, -32821 and -32825 . Of these, Beta-32817 and -32821 , from the main trench actually overlap stratigraphically related samples at $2 \sigma$; as can be seen in the diagram; however, their calibrated ranges are extremely long, extending to A.D. 1955. Thus, they can be discounted as being of little use in determining an age-depth curve for the site. The third apparently aberrant sample, Beta-32825, comes from the stratigraphically complex grid unit $\mathrm{F} 30$, in which a number of prehistoric pits had been excavated into the deeper, ashy midden deposits in the basal portion of the section. It is probable that the charcoal dated in this sample actually derived from the earliest occupation phase (analytic zone I), and had been displaced by a pit dug during deposition of analytic zone $\mathrm{G}$.

In general, the ${ }^{14} \mathrm{C}$ ages from Tangatatau fall into a consistent age-depth sequence beginning about cal. A.D. 1000-1100 and extending up until about cal. A.D. 1500-1600. Thus, it appears that the site was occupied more or less continuously over a period of some $4-6$ centuries. This period was one

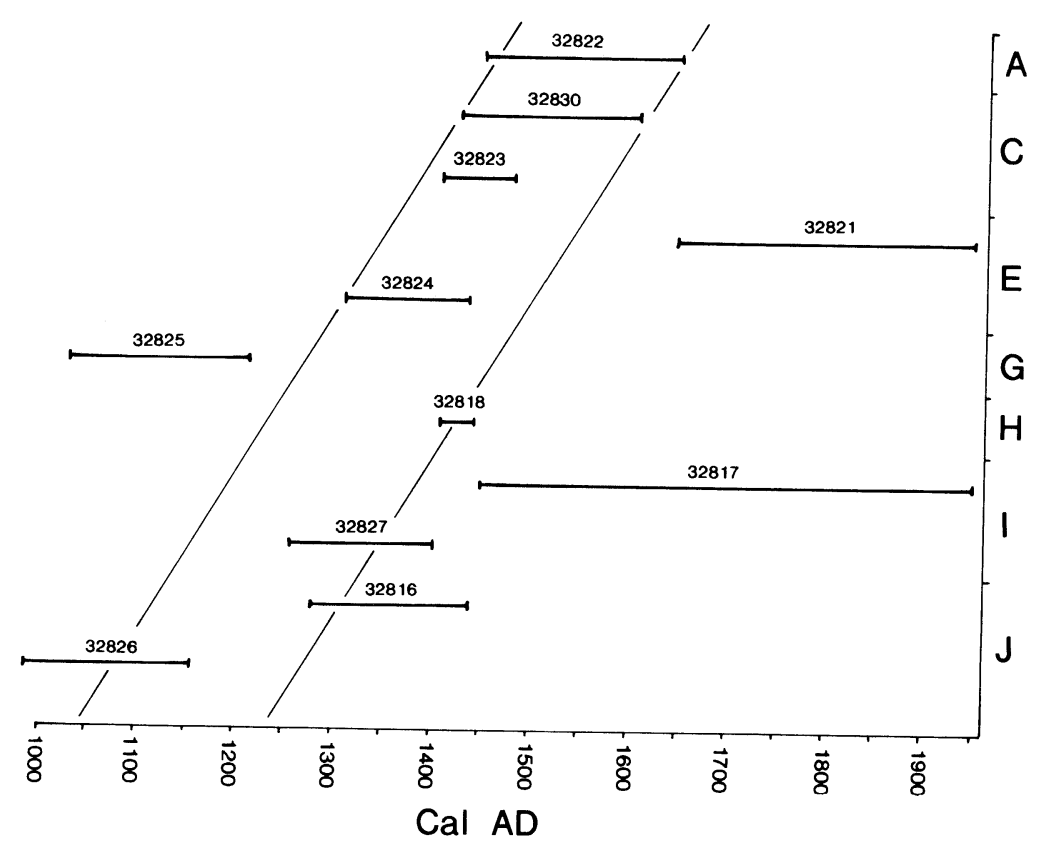

Fig. 2. Radiocarbon age determinations from the main excavation trench in Tangatatau rockshelter, plotted as cal. A.D. ages at $1 \mathrm{o}$, arrayed according to analytic zones (i.e., in stratigraphic position) 


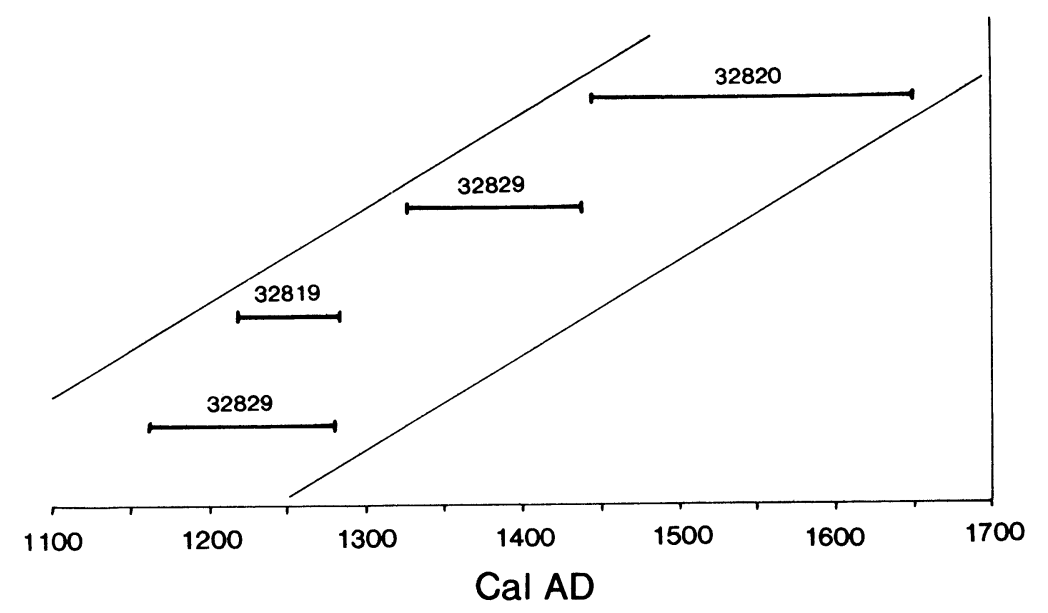

Fig. 3. Radiocarbon age determinations from grid unit F10 in Tangatatau rockshelter, plotted as cal. A.D. ages at $1 \sigma$, arrayed according to stratigraphic position

of major changes in Mangaian culture and ecology, as witnessed by changes in the artifactual and faunal assemblages (Steadman \& Kirch 1990; Kirch \& Steadman, ms. in preparation). Further, the two oldest ${ }^{14} \mathrm{C}$ ages from Tatangatau provide the earliest artifactual evidence of human occupation on Mangaia.

\section{THE LAKE TIRIARA RADIOCARBON SEQUENCE}

In order to obtain sediment samples for palynological analysis and determination of changes in the island's vegetational history, three cores were taken in Lake Tiriara (Fig. 1). The sedimentology of the cores was studied by Dawson (1990). Core TIR 1 was taken in the approximate center of the lake (water depth $2.1 \mathrm{~m}$ ), from a floating platform constructed of inner tubes and plywood. TIR 1 had a total length of $14.89 \mathrm{~m}$, and consisted largely of organic lacustrine sediment (gyttja) with some clay banding, particularly in the upper portion of the core. Core TIR 2 was taken at the edge of the swamp bordering the lake ( $c a .49 \mathrm{~m}$ from TIR 1), and had a total depth of $11.55 \mathrm{~m}$. The upper $4 \mathrm{~m}$ of this core consist primarily of clay, grading into gyttja with clay and charcoal banding in the deeper portions of the core. Core TIR 3 was taken farther away from the lake into the swampy valley bottom; the total depth of TIR 3 was $12.47 \mathrm{~m}$. As in TIR 2, the upper portion of this core consisted dominantly of clays, grading into peats and gyttja in the deeper portions.

Eight sediment samples from the Lake Tiriara cores were submitted for ${ }^{14} \mathrm{C}$ determination, 6 from TIR 1 , and 1 each from TIR 2 and 3 . The samples were pretreated by first picking for any rootlets; they were then dispersed in hot acid to eliminate carbonates, repeatedly rinsed to neutrality, dried and combusted in an enclosed system (M. Tamers, personal communication, 5 Oct. 1989). All benzene syntheses and countings proceeded normally. Conventional ${ }^{14} \mathrm{C}$ ages, ${ }^{13} \mathrm{C} /{ }^{12} \mathrm{C}$ values, and relevant sample information for these samples are presented at the end of this paper.

The Lake Tiriara pollen core sample ages are plotted in Figure 4 as 1 o cal. B.P. age ranges, arrayed by depth below the surface of the deposit. All eight samples display a remarkably clear and consistent age-depth progression, and suggest that the lake and valley-bottom swamp system, of which it is a part, have had a fairly constant rate of infilling over the past 6500 years. The sedi- 


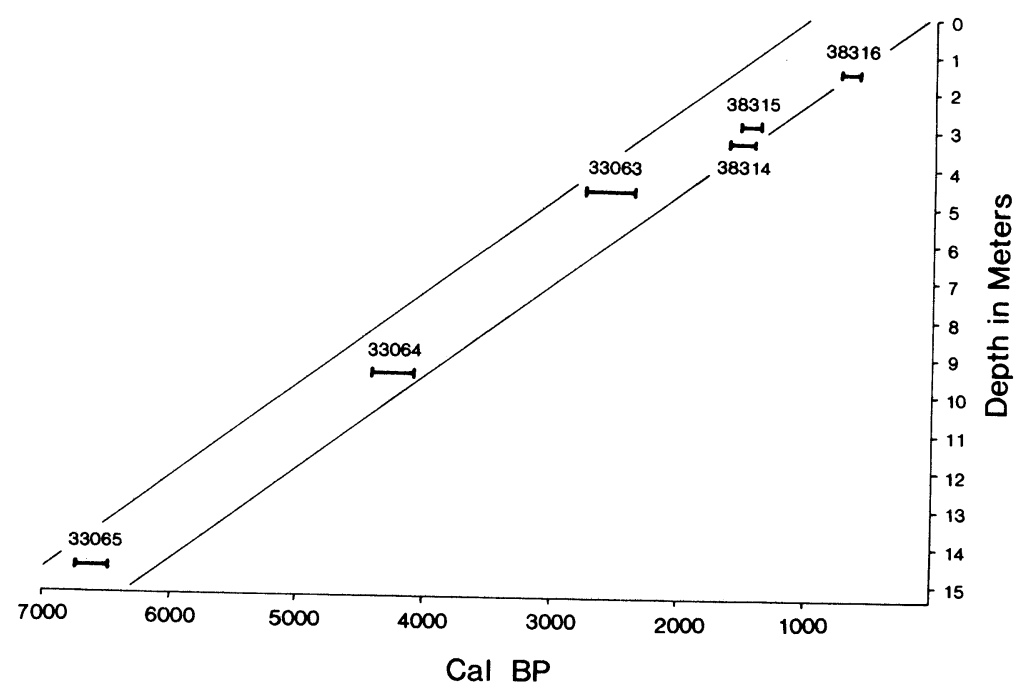

Fig. 4. Radiocarbon age determinations from the TIR-1 Lake Tiriara pollen core, plotted as cal. B.P. ages at $1 \sigma$, according to depth in meters below the surface. Note that all six ages suggest a regular age-depth curve.

mentary change in the TIR-2 and -3 cores, from peat and gyttja to clays in the upper $4 \mathrm{~m}$, apparently took place after about 2000 B.P.

Lamont (1990) has analyzed the pollen record of the TIR core, which provides a vegetation history for Mangaia spanning the past 6500 years. Details of this sequence, and its correlation with the island's archaeological sequence, will be discussed at greater length elsewhere. Briefly, the pollen record can be divided into three zones. Zone 3 , at the base of the TIR 1 core, dates between about 6500 and 6000 cal. B.P., and displays a relatively "high proportion of tree pollen," dominated by Weinmannia (Cunoniaceae) and Meryta (Araliaceae) (Lamont 1990: 30-31). There is some indication of disturbance towards the middle of Zone 3, possibly due to the effects of tropical cyclones. Zone 2 dates from about 6000 to 1600 cal. B.P. This zone is again marked by a relatively high proportion of tree pollen and low frequency of ferns. The effects of rising Holocene sea levels at about 3700 cal. B.P. are suggested by the appearance of Rhizophoraceae, and corroborate geomorphological indications of an approximately $+1 \mathrm{~m}$ seastand at this time (Yonekura et al. 1988). The most dramatic change in the pollen record occurs in Zone 1, dated from about 1600 cal. B.P. to the present. This zone is "marked by a significant decrease in the tree pollen and the disappearance of primary taxa such as Weinmannia" (Lamont 1990: 34). There is also a dramatic increase in fern spore frequencies, such as Dicranopteris (Gleichenia), and increases in secondary taxa. There appears to be little doubt that Zone 1 reflects the impacts of prehistoric Polynesian forest clearance on the central volcanic cone of Mangaia. This forest clearance resulted in substantial erosion and creation of the pyrophytic fern-Pandanus association that has dominated the volcanic interior in historic times.

The Zone 2/Zone 1 boundary is bracketed by ${ }^{14} \mathrm{C}$ determinations Beta-38314 and -38315 . These suggest that the onset of Polynesian forest clearance began between about 1600 and 1400 cal. B.P. This is several hundred years earlier than the age of the basal cultural deposits in the Tangatatau rockshelter. We believe that the pollen record may be a better indicator of the probable age of initial human colonization of Mangaia, i.e., early in the first millennium A.D. 


\section{DISCUSSION AND IMPLICATIONS}

The radiocarbon age determinations reported herein are the first to be reported from Mangaia in association with cultural materials, and provide both the first chronometric evidence for the span of human occupation of the island, and also critical information on the timing of major environmental changes. The radiocarbon series from Tangatatau rockshelter indicates that prehistoric Polynesians were well established on the island by ca. A.D. 1000-1100. These Polynesians had introduced the rat (Rattus exulans), chicken (Gallus gallus) and pig (Sus scrofa), and were exploiting a broad spectrum of indigenous and endemic birds, fruit bats, sea turtles, fishes and invertebrates for food. They manufactured one-piece fishhooks from imported pearl-oyster shell (Pinctada sp.), and also used a variety of other typical East Polynesian artifacts.

It is unlikely, however, that the basal levels of the Tangatatau site represent an initial colonization phase. The presence of large numbers of extinct bird bones in the early levels of Tangatatau might be taken as evidence that the site was occupied at the beginning of the island's prehistoric cultural sequence. However, these basal levels in Tangatatau may simply represent a phase of local impact on the Veitatei District fauna, some time after first colonization of the island by humans. This latter alternative is reinforced by the evidence of the Lake Tiriara pollen record, which shows accelerated erosion of the central volcanic core and significant decreases in tree pollen along with increases in fern spores, beginning about 1600 cal. B.P.

Polynesians clearly had a dramatic impact on the island's ecology during the past 1600 years. This is most evident in the extinction and extirpation of no less than nine species of landbirds (rails, pigeons, doves and parrots). However, human impact is also evident in the significant reductions in numbers of fruit bat (Pteropus tonganus), and in size reductions in mollusks gathered for food from the narrow fringing reef. Another kind of impact is suggested by the changes in the Lake Tiriara sedimentary regime, with a shift to dominantly clay sediments in the upper levels. This is correlated with forest clearance on the central volcanic cone (as a result of horticultural activities), thereby inducing erosion of the lateritic soils. In sum, the archaeological, geomorphological and palynological evidence obtained from Mangaia during our 1989 investigations document a sequence of pronounced anthropogenic impacts on this island ecosystem. It is our intention to explore this sequence of ecological change further, and to study its effects on the evolution of Mangaian culture and society, through continued field and laboratory investigations.

\section{ACKNOWLEDGMENTS}

The 1989 Mangaia Project was supported by Grant 4001-89 from the National Geographic Society Committee on Research and Exploration. Bone analyses were supported by National Science Foundation Grant BSR-8607535. Permission to conduct field studies on the island was graciously granted by the Government of the Cook Islands and by the Mangaian Island Council. We are especially grateful to the following individuals who greatly assisted our work in the Cook Islands: Tony Utanga, Makiuti Tongia, Tua Uria, Papamama Pokino, Ma'ara Ngu, Nga Ruatoe, Peter Ngatokorua, Paiti Kareroa and George Tuara. The authors were also assisted in the field by Melinda Allen, Stuart Dawson, Frances Lamont and Virginia Carter Steadman. N. G. Miller commented on the manuscript. This is Contribution No. 671 of the New York State Science Service. 


\section{ARCHAEOLOGICAL SAMPLES}

\section{Tangatatau Site series}

Beta-32816. Tangatatau

$550 \pm 120$

$\delta^{13} \mathrm{C}=-27.3 \%$

Site MAN-44, Unit E30, W face. Charcoal from under roof-fall limestone boulder. Analytic zone J. (Field sample no. C-1) Extended counting time sample (0.29 g carbon). Cal. A.D. 1280 (1407) 1440 at $1 \sigma$; cal. B.P. 670 (543) 510 at $1 \mathrm{o}$.

Beta-32817. Tangatatau

$230 \pm 160$

$\delta^{13} \mathrm{C}=-28.1 \% 0$

Site MAN-44, Unit C30, Level 10. S half of unit. $1.2-1.3 \mathrm{~cm}$ below surface. Charcoal. Analytic zone I (correlation tentative). (Field sample no. C-2) Extended counting time sample (0.24 g carbon). Cal. A.D. 1450 (1656) 1955 at $1 \sigma$; cal. B.P. 500 (294) 0 at $1 \sigma$.

Beta-32818. Tangatatau

$$
\delta^{13} C=\begin{array}{r}
\mathbf{4 9 0} \pm \mathbf{5 0} \\
-26.6 \% 0
\end{array}
$$

Site MAN-44, Unit F30, Level 10. From charcoal concentration in NW corner of unit, 1.36 $\mathrm{cm}$ below surface. Analytic zone H. (Field sample no. C-3) Cal. A.D. 1409 (1426) 1440 at 1 o; cal. B.P. 541 (524) 510 at $1 \mathrm{o}$.

Beta-32819. Tangatatau

$$
\delta^{13} C=\begin{array}{r}
\mathbf{7 4 0} \pm \mathbf{8 0} \\
-26.9 \%
\end{array}
$$

Site MAN-44, Unit F10, Level 8. Feature 2, at $1.23 \mathrm{~cm}$ below datum. Single large piece of wood charcoal. (Field sample no. C-4) Cal. A.D. 1218 (1277) 1285 at 1 o; cal. B.P. 732 (673) 665 at $1 \sigma$.

Beta-32820. Tangatatau

$$
\delta^{13} \mathrm{C}=\begin{array}{r}
\mathbf{3 3 0} \pm \mathbf{8 0} \\
-26.0 \% 0
\end{array}
$$

Site MAN-44, Unit F10, Level 2. (Field sample no. C-5). Cal. A.D. $1446(1521,1590,1623)$ 1650 at $1 \sigma$; cal. B.P. $504(429,360,327) 300$ at $1 \sigma$.

Beta-32821. Tangatatau

$$
\delta^{13} C=\begin{array}{r}
200 \pm 60 \\
-26.8 \%
\end{array}
$$

Site MAN-44, Unit G30, Level 4. Charcoal from earth oven. Analytic zone E. (Field sample no. C-6). Cal. A.D. $1647(1665,1784,1788,1949,1952) 1955$ at 1 o; cal. B.P. $303(285,166,162$, $1,0) 0$ at $1 \sigma$.

\section{Beta-32822. Tangatatau}

$$
\delta^{13} C=\begin{array}{r}
\mathbf{3 3 0} \pm \mathbf{8 0} \\
-26.7 \% \circ
\end{array}
$$

Site MAN-44, Unit E30, Level 2. Charcoal from approximately $66 \mathrm{~cm}$ below surface. Analytic zone A. (Field sample no. C-7) Cal. A.D. $1446(1521.1590,1623) 1650$ at $1 \sigma$; cal. B.P. 504 (429, $360,327) 300$ at $1 \mathrm{o}$. 
Beta-32823. Tangatatau

Site MAN-44, Unit F30, Level 3. Analytic zone C. (Field sample no. C-8) Cal. A.D. 1414 (1437) 1480 at $1 \sigma$; cal. B.P. 536 (513) 470 at $1 \sigma$.

Beta-32824. Tangatatau

$540 \pm 80$

$\delta^{13} \mathrm{C}=-29.5 \% 0$

Site MAN-44, Unit D30, Level 6; $1.18 \mathrm{~cm}$ below datum. Analytic zone E. (Field sample no. C-9) Extended counting time sample (0.54 g carbon). Cal. A.D. 1311 (1410) 1435 at $1 \sigma$; cal. B.P. $639(540) 515$ at $1 \sigma$.

Beta-32825. Tangatatau

$900 \pm 70$

$\delta^{13} \mathrm{C}=-27.0 \%$

Site MAN-44, Unit F30, Level 9. Analytic zone G. (Field sample no. C-10). Extended counting time sample $(0.81 \mathrm{~g}$ carbon). Cal. A.D. $1024(1133,1136,1156) 1216$ at $1 \sigma$; cal. B.P. 926 $(817,814,794) 734$ at $1 \sigma$.

Beta-32826. Tangatatau $980 \pm 70$ $\delta^{13} \mathrm{C}=-27.3 \%$

Site MAN-44, Unit E30, Level 13. Charcoal from small lens at contact of levels $12-13 ; 1.54$ $\mathrm{cm}$ below datum. Analytic zone J. (Field sample no. C-11) Extended counting time sample (0.61 g carbon). Cal. A.D. 988 (1023) 1155 at $1 \sigma$; cal. B.P. 962 (927) 795 at $1 \sigma$.

Beta-32827. Tangatatau

$700 \pm 80$ $\delta^{13} \mathrm{C}=-27.9 \%$

Site MAN-44, Unit C30, Level 11. Charcoal in pit fill. Analytic zone I. (Field sample no. C-12) Cal. A.D. 1259 (1280) 1387 at 1 o; cal. B.P. $691(670) 563$ at 1 o.

Beta-32828. Tangatatau

$790 \pm 80$

$\delta^{13} \mathrm{C}=-27.7 \%$

Site MAN-44, Unit F10, Level 8. Charcoal from Feature 2, $1.23 \mathrm{~cm}$ below datum. (Field sample no. C-13) Cal. A.D. 1162 (1257) 1280 at 1 o; cal. B.P. 788 (693) 670 at $1 \sigma$.

$520 \pm 70$

Beta-32829. Tangatatau

$\delta^{13} \mathrm{C}=-27.2 \%$

Site MAN-44, Unit F10, Level 3. Charcoal at base of level 3, at contact of midden deposit with reddish silty-clay subsoil. (Field sample no. C-14) Extended counting time sample $(0.67 \mathrm{~g}$ carbon). Cal. A.D. 1327 (1415) 1438 at 1 o; cal. B.P. 623 (535) 512 at $1 \sigma$.

Beta-32830. Tangatatau $420 \pm 70$ $\delta^{13} \mathrm{C}=-26.4 \%$

Site MAN-44, Unit F30, Level 3. Charcoal from thin lens, collected in situ, $0.69 \mathrm{~cm}$ below datum. Analytic zone C. (Field sample no. C-15) Cal. A.D. 1425 (1443) 1612 at 1 o; cal. B.P. 525 (507) 338 at $1 \sigma$. 


\section{PALYNOLOGiCAL SAMPLES}

\section{Lake Tiriara series}

Beta-33063. Lake Tiriara

$$
\delta^{13} \mathrm{C}=-27.2 \% 0
$$

Sediment from core TIR 1, 4-61-4.71 m depth. Cal. BC $778(752,709,530) 403$ at 1 o; cal. B.P. $2727(2701,2658,2479) 2352$ at $1 \sigma$.

Beta-33064. Lake Tiriara

$3860 \pm 90$

$\delta^{13} \mathrm{C}=-27.7 \%$ 。

Sediment from core TIR 1, 9.60-9.70 m depth. Cal. BC 2468 (2343) 2149 at 1 o; cal. B.P. 4417 (4292) 4098 at $1 \sigma$.

Beta-33065. Lake Tiriara

$5810 \pm 100$

$\delta^{13} \mathrm{C}=-26.8 \%$

Sediment from core TIR 1, 14.75-14.85 m depth. Cal. BC 4790 (4719) 4545 at 1 o; cal. B.P. $6739(6668) 6494$ at $1 \sigma$.

Beta-33066. Lake Tiriara

$4770 \pm 80$

$\delta^{13} \mathrm{C}=-25.1 \%$

Sediment from core TIR 2, 12.65-12.75 m depth. Cal. BC $3646(3619,3576,3531) 3382$ at $1 \sigma$; cal. B.P. $5595(5568,5525,5480) 5331$ at 1 o.

Beta-33067. Lake Tiriara

$$
\begin{array}{r}
3820 \pm \mathbf{8 0} \\
\delta^{13} C=-26.0 \% 0
\end{array}
$$

Sediment from core TIR 3, 9.85-9.95 m depth. Cal. BC 2458 (2288) 2142 at 1 o; cal. B.P. 4407 (4237) 4091 at $1 \sigma$.

Beta-38314. Lake Tiriara

$1640 \pm 50$

$\delta^{13} \mathrm{C}=-25.0 \%$

Sediment from core TIR 1, 3.3-3.4 m depth. This sample lies just below the Zone 2/Zone 1 boundary of the pollen sequence. CaI. A.D. 343 (411) 527 at 1 o; cal. B.P. 1607 (1539) 1423 at $1 \sigma$.

Beta-38315. Lake Tiriara

$$
\begin{array}{r}
1550 \pm 60 \\
\delta^{13} C=-25.0 \% \circ
\end{array}
$$

Sediment from core TIR 1, 2.8-2.9 $\mathrm{m}$ depth. This sample lies just above the Zone $1 /$ Zone 2 boundary of the pollen sequence. Cal. A.D. $426(482,488,534) 572$ at 1 o; cal. B.P. 1524 (1468, $1462,1416) 1378$ at $1 \sigma$.

Beta-38316. Lake Tiriara

$1350 \pm 110$

$$
\delta^{13} \mathrm{C}=-25.0 \%
$$

Sediment from core TIR 1, 1.5-1.6 m depth. Cal. A.D. 600 (661) 770 at 1 o; cal. B.P. 1350 (1289) 1180 at $1 \sigma$. 


\section{REFERENCES}

Bellwood, P. 1978 Archaeological research in the Cook Islands. Pacific Anthropological Records 27: 1-214.

Buck, P. H. 1934 Mangaian society. B. P. Bishop Museum Bulletin 122: 1-207.

Christensen, C. C. and Kirch, P. V. 1986 Nonmarine molluscs and ecological change at Barbers Point, O'ahu, Hawai'i. Occasional Papers of the B. P. Bishop Museum 26: 52-80.

Dawson, S. (ms.) 1990 A chemical and mineralogical study of a sediment core from Lake Tiriara, Mangaia, Southern Cook Islands, with special reference to the impact of early man. B. Sc. dissertation, School of Geography and Earth Resources, The University of Hull.

Flenley, J. R. and King, S. M. 1984 Late Quaternary pollen records from Easter Island. Nature 307:47-50.

Fosberg, R. 1963 Disturbance in island ecosystems. In Gressit, J. L., ed., Pacific Basin Biogeography. Honolulu, Bishop Museum Press: 557-561.

Gill, W. W. 1894 From Darkness to Light in Polynesia. London, The Religious Tract Society.

Hughes, P., Hope, G., Latham, M. and Brookfield, H. 1982 Prehistoric man-induced degradation of the Lakeba landscape. evidence from two inland swamps. In Brookfield, H., ed., Lakeba: Environmental Change, Population Dynamics, and Resource Use. Paris, UNESCO: 93-110.

Kirch, P. V. 1982 The impact of the prehistoric Polynesians on the Hawaiian ecosystem. Pacific Science 36: $1-14$.

1983 Man's role in modifying tropical and subtropical Polynesian ecosystems. Archaeology in Oceania 18: 26-31.

Kirch, P. V. and Yen, D. E. 1982 Tikopia: The prehistory and ecology of a Polynesian outlier. B. P. Bishop Museum Bulletin 238: 1-396.

Lamont, F. (ms.) 1990 A 6,000 year pollen record from Mangaia, Cook Islands, South Pacific: Evidence for early human impact. B. Sc. dissertation, School of Geography and Earth Resources, The University of Hull.

MacArthur, R. and Wilson, E. O. 1967 The theory of island biogeography. Monographs in Population Biology 1, Princeton.

Marshall, P. 1927 Geology of Mangaia. B. P. Bishop Museum Bulletin 36: 1-48.

McGlone, M. 1983 The Polynesian deforestation of New Zealand: A preliminary synthesis. Archaeology in Oceania 18: 11-25.

Merlin, M. D. 1991 Woody vegetation on the raised coral limestone of Mangaia, southern Cook Islands. Pacific Science 45: 131-151.
Olson, S. L. and James, H. F. 1984 The role of Polynesians in the extinction of the avifauna of the Hawaiian Islands. In Martin, P. S. and Klein, R. G., eds., Quaternary Extinctions. Tucson, University of Arizona Press: 768-780.

Pregill, G. K. and Dye, T. 1989 Prehistoric extinction of giant iguanas in Tonga. Copeia 1989(2): 505-508.

Spriggs, M. 1986 Landscape, land use and political transformation in southern Melanesia. In Kirch, P. V., ed., Island Societies: Archaeological Approaches to Evolution and Transformation. Cambridge, Cambridge University Press: 6-19.

Steadman, D. W. 1985 Fossil birds from Mangaia, Southern Cook Islands. Bulletin of the British Ornithologists' Club 108: 58-66.

1987 Two new species of rails (Aves: Rallidae) from Mangaia, Southern Cook Islands. Pacific Science 40: 27-43.

1989 Extinction of birds in Eastern Polynesia: A review of the record, and comparisons with other Pacific Island groups. Journal of Archaeological Science 16: 177-205.

Steadman, D. W. and Kirch, P. 1990 Prehistoric extinction of birds on Mangaia, Cook Islands, Polynesia. Proceedings of the National Academy of Sciences 87: 9605-9609.

Stoddart, D. R., Spencer, T. and Scoffin, T. P. 1985 Reef growth and karst erosion on Mangaia, Cook Islands: A reinterpretation. Zeitschrift fuer Geomorphologie 57: 121-140.

Stuiver, M. and Becker, B. 1986 High-precision decadal calibration of the radiocarbon time scale, A.D. 19502500 B.C. In Stuiver, M. and Kra, R. S., eds., Proceedings of the 12 th International ${ }^{14} \mathrm{C}$ Conference. Radiocarbon 28(2B): 863-910.

Stuiver, M. and Polach, H. A. 1977 Discussion: Reporting of ${ }^{14} \mathrm{C}$ data. Radiocarbon 19(3): 355-363.

Stuiver, M. and Reimer, P. J. 1986 A computer program for radiocarbon age calibration. In Stuiver, M. and Kra, R. S., eds, Proceedings of the 12th International ${ }^{14} \mathrm{C}$ Conference. Radiocarbon 28(2B): 1022-1030.

Turner, D. L. and Jarrard, R. D. 1982 K-Ar dating of the Cook-Austral island chain. a test of the hot-spot hypothesis. Journal of Volcanology and Geothermal Research 12: 187-220.

Yonekura, N., Ishii, T., Saito, Y., Maeda, Y., Matsuhima, Y., Matsumoto, E. and Kayanne, H. 1988 Holocene fringing reefs and sea-level change in Mangaia Island, Southern Cook Islands. Palaeogeography, Palaeoclimatology, Palaeoecology 68: 177-188. 